\title{
DIFFERENTIATION OF TWO PLEUROTUS SPECIES BASED ON THE RESTRICTIVE DIGESTION PROFILE OF THE INTERNAL TRANSCRIBED SPACER REGION
}

\author{
M. Wiafe-Kwagyan*, G. T. Odamtten And M. Obodai \\ (M. W-K. \& G. T. O.: University of Ghana, Department of Plant and Environmental \\ Biology, P.O. Box 55, Legon, Accra; M. O.: Council for Scientific and Industrial Rese \\ arch - Food Research Institute, Food Microbiology Division, \\ P. O. Box M20, Accra, Ghana). \\ *Corresponding author's email: mwiafe-kwagyan@ug.edu.gh,wiakwa@yahoo.com
}

\begin{abstract}
Two oyster mushrooms (Pleurotus eous P-31 and P. ostreatus EM-1) are under either cottage industry or semi-commercial cultivation in Ghana. The latter ( $P$. ostreatus) is already well known to the public and on the shelf of some leading supermarkets. There is morphological resemblance between the two species making it difficult for the untrained eye to distinguish between them except for the colour difference. In this study, molecular methods were employed to differentiate among the two species. The Internal Transcribed Spacer ITS 1 and ITS 4 regions of the rDNA of the two oyster species were amplified by the conventional PCR using the universal primer pair, ITS 1 and ITS 4 followed by restrictive digestion with enzymes, (Hh I, Hinf I, Rsa I and Hae III). The two species could not be separated based on the amplified bands only, as both produced a characteristic band size of $650 \mathrm{bp}$. Gel profiling showing restrictive patterns generated by the four enzymes indicated that only the Hae III restrictive enzyme was effective in separating P. eous $\mathrm{P}-31$ and P. ostreatus EM-1. This is the first record of the separation of the Ghanaian Pleurotus species by molecular methods indicating their genetic differences.
\end{abstract}

Keywords: PCR amplification, ITS region, rDNA, restrictive enzymes, Pleurotus eous P-31, P. ostreatus EM-1

\section{Introduction}

Mushrooms have been an important food item in human health, nutritional and disease prevention (Chang, 1999). Dietary mushrooms provide a wide variety of medicinal properties and they are effective against certain lifethreatening diseases. The major medicinal properties attributed to mushrooms include anticancer, antibiotic, antiviral activities, immunity, and blood lipid lowering properties, antidiabetic, antihypertensive, etc., (Wong et al., 2010; Kim et al., 2011; Patel, Narian \& Singh, 2012; Roupas, et al., 2012; Jesenak et al., 2015 etc.).
The term mushroom applies to fungi with distinct fruiting body, fleshy in nature having tough umbrella-like structure called cap (pileus), carried on stipe (stem). The cap bear basidia (spore-bearing structures) on the surface of gills or plate (lamellae). The distinct fruiting bodies can either occur above the soil (epigeous) or below (hypogenous) soil or on decaying wood (cespitose or caestipose) (Chang \& Miles, 2004).

Oyster mushrooms (Pleurotus spp.) are useful medicinally and are cultivated in many countries including China, Japan, 
India, South East Asia, USA, the Netherlands and recently introduced to Africa (Nigeria, Ghana, Bénin, Burkina Faso, Cameroon, Cote d'Ivoire, Egypt, Ethiopia etc.) (Obodai, 1992; Atikpo et al., 2008; Osarenkhoe et al., 2014; Jongman, Khare \& Loeto., 2018). They are edible mushroom belonging to the family Pleurotaceae (Randive, 2012). There are several strains of Pleurotus (P. pulmonarius $=$ Lentinus sajor-caju, $P . \quad$ sajor-caju, $P$. eryngii, P. eousmus, P. ostreatus, P. tuberregium $=$ Lentinus tuber-regium, $P$. cystidiosus, P. cornucopiae, P. florida, P. citrinopileatus, $P$. eous, P. djamor etc.) (Bresinsky et al., 1987; Obodai \& Vowotor, 2002; Kang, 2004; OECD, 2005; Patil et al., 2010; Shukla \& Jaitly, 2011; Obodai et al., 2014, Piska, Sułkowska-Ziaja, \& Muszyńska, 2017 etc.). Oyster mushrooms (Pleurotus spp.) are very effective in reducing total plasma cholesterol and triglyceride levels in humans (Nuhu et al., 2008) and thus reduce the chance of atherosclerosis and other cardiovascular and artery related disorders.

Pleurotus species also have antitumour activity and antitumor activities (Nayana \& Janardhanan, 2000; Manpret et al., 2004). Chemical analyses of fruiting body show that P. ostreatus contains Ascorbic acid (Vitamin C), Thiamine (Vitamin B1); Folic Acid (Vitamin B), Niacin (Vitamin B3), Riboflavin (Vitamin B2) (Patil et al., 2010; Kortei et al., 2016; Nasiruddin et al., 2018; ObinaEchem \& Churunda, 2018) as well as essential amino acids such as leucine, valine, lysine, isoleucine, threonine, tyrosine, methionine and phenylalanine (Oyetayo et al., 2007; Patil et al., 2010; Khan \& Tania, 2012; Obodai et al., 2014). Appreciable levels of energy, carbohydrates, crude protein, lipids, fibre, ash, sugar alcohol, glycogen, chitin have been detected in P. ostreatus (Bhatti et al., 2007; Daba et al., 2008; Hung \& Nhi, 2012).
The oyster mushroom $P$. ostreatus cultivated in Ghana contained 49.93\% total carbohydrates, $20.02 \%$ crude protein, $2 \%$ lipids, $15.8 \%$ crude fibre, $7.62 \%$ ash, $279.92 \mathrm{Kcal} / 100 \mathrm{~g}, \quad \mathrm{Ca} \quad(43.06 \mathrm{mg} / 100 \mathrm{~g})$, P $(939.0 \mathrm{mg} / 100 \mathrm{~g}), \quad \mathrm{K} \quad(3334 \mathrm{mg} / 100 \mathrm{~g}), \quad \mathrm{Fe}$ $(42.65 \mathrm{mg} / 100 \mathrm{~g})$, and Ascorbic Acid (Obodai, 1992; Obodai et al., 2014; Kortei et al., 2016; Wiafe-Kwagyan et al., 2016). Studies in Ghana by Wiafe-Kwagyan (2014) and Wiafe-Kwagyan et al. (2016) have shown the fruit bodies of $P$. eous contained $\mathrm{Ca}, \mathrm{Fe}$, $\mathrm{K}, \mathrm{Mg}, \mathrm{Na}, \mathrm{P}$ as well as $\mathrm{Cu}, \mathrm{Zn}, \mathrm{Pb}, \mathrm{Mn}$, in varying quantities depending on the substrate formulation. In most instances, the levels of nutrients and elements detected in $P$. eous was higher than what existed in $P$. ostreatus (Wiafe-Kwagyan, 2014; Kortei et al., 2016; Wiafe-Kwagyan et al., 2016, 2017). This may imply genetic difference between the two Pleurotus species.

Geographical and climatic difference between tropical areas do not always allow the extension of results of knowledge of research into new regions. It is therefore necessary to investigate, using local conditions in order to arrive at data which will provide clearly defined techniques for the cultivation of a particular species without extra cost. Although morphological features and colour characteristics are important in the elucidation of the Biological Efficiency (BE) and identification of mushrooms, this may be elusive in some instances. The current trend is to use molecular and biochemical techniques to complement observed conventional taxonomic features.

Recent molecular polygenic studies have demonstrated that the ITS (Internal Transcribed Spacer) region of genomic DNA is very useful in assessing polygenetic relationship at lower taxonomic levels. The 
variations of the ITS of rDNA of organisms is considered as sufficient for distinguishing among species and even among strains (Vilgalys et al., 1993; Zervakis et al., 1994; Iracabal et. al., 1995).

In this paper the ITS 1 and ITS 4 regions of the rDNA of $P$. eous strain P-31 and $P$. ostreatus strain EM-1 were amplified by PCR techniques using universal primers (Hh I, Hindf I, RSa I and Hae III) with the view to ascertaining their primary taxonomic status and also obtain an ancillary information to elucidate their comparative growth performance, Biological Efficiency and the differential level of elemental composition and nutrient status.

\section{Experimental}

Morphological and cultural differences

between P. eous and P. ostreatus

Cultures of P. eous P-31 and P. ostreatus EM-1 were raised on Potato Dextrose Agar and Malt Extract Agar and incubated at $28-30^{\circ} \mathrm{C}$ for 7 days. P. eous appears whiter than P. ostreatus with profuse mycelia on Potato Dextrose Agar and Malt Extract Agar. Photograph of the cultures were taken after the incubation period. The pictures of mature fruiting bodies of both Pleurotus species from the cropping house were taken for record purposes and the gill regions were captured by camera as well as the gross morphology.

Extraction of DNA from dry mushroom sample Total genomic DNA was isolated and purified using E.Z.N.A. TM SP Plant DNA Mini Kit. $0.3 \mathrm{~g}$ of dried ground mushroom samples was weighed into a microfuge tube. $700 \mu \mathrm{L}$ of Buffer SP1 was added followed by $5 \mu \mathrm{L}$ of RNase A after which samples were incubated at $65{ }^{\circ} \mathrm{C}$ for 15 minutes. Two hundred and ten micro litres of buffer SP2 was added and the samples were mixed vigorously by vortex followed by incubating samples on ice for 5 minute and centrifuged at $14000 \mathrm{rpm}$ for 10 minutes. The supernatant obtained was carefully aspirated into an Omega ${ }^{\circledR}$ Homogenizer Column placed in $2 \mathrm{~mL}$ collection tube and was then centrifuged at $14000 \mathrm{rpm}$ for 2 minutes. $500 \mu \mathrm{L}$ of the clear lysate that resulted was transferred into to a $1.5 \mathrm{~mL}$ tube. Binding conditions of the sample was adjusted by pipetting $750 \mu \mathrm{L}$ of buffer sp3/ ethanol mixture directly on to cleared lysate. $650 \mu \mathrm{L}$ of the resulting mixture was transferred into a Hiband $\mathbb{R}$ DNA Mini Column placed in a $2 \mathrm{~mL}$ collection tube and centrifuged for 1 minute at $14000 \mathrm{rpm}$ after which the flow through was discarded. This was repeated for the remaining mixture. The columns were placed into a new $2 \mathrm{~mL}$ collection tube and $650 \mu \mathrm{L}$ of SPW Wash Buffer diluted with ethanol was added. This was centrifuged at $14000 \mathrm{rpm}$ for 1 minute and the flow through discarded. This step was repeated with the sample volume of buffer SPW wash buffer. The empty column was centrifuged at 14000 rpm for 2 minutes. The Hiband ${ }^{\circledR}$ Mini column was then transferred into a sterile $1.5 \mathrm{~mL}$ tube and $100 \mu \mathrm{L}$ of pre-warmed $\left(65^{\circ} \mathrm{C}\right)$ elution buffer was added. This was then centrifuged at $14000 \mathrm{rpm}$ for 1 minute to elute DNA based on the manufacturer's instructions.

\section{Polymerase Chain Reaction (PCR) amplification}

PCR was performed with ITS 1 and ITS 4 primer to characterize the ITS region of mushroom samples. ITS amplification was carried out in a $25 \mu \mathrm{L}$ PCR reaction composed of 1X GoTaq PCR master mix, $0.2 \mu \mathrm{M}$ each of ITS 1 and ITS 4 primers and $1 \mu \mathrm{L}$ of extracted DNA. The thermal cycling conditions were as follows; 94 for $5 \mathrm{~min}$ followed by 35 cycles of 94 for $1 \mathrm{~min}, 55$ for $1 \mathrm{~min}$ and 72 for $2 \mathrm{~min}$, and a final extension at 72 for $6 \mathrm{~min}$. Products were run and visualized on a $1.5 \%$ agarose matrix stained with ethidium bromide as prescribed by manufacturers. 


\section{Restriction digestion}

Restriction enzymes were used to segregate the two mushroom species based on the generated restriction patterns of ITS 1 and ITS 4 amplicons following the manufacturer's guidelines. Final volumes were made with deionized water.

\section{Results and discussion}

Morphological differences of the two species were hard to distinguish except for the size and length of the stipe and colour of pileus (cap). The pileus of $P$. eous strain P-31 was whitish (Fig. 1) while that of P. ostreatus strain EM-1 was greyish brown to dark brown (Fig. 2). The emergence of the fruiting body was cespitose (or caestipose) and similar for both P. eous and P. ostreatus. The photograph of the gill regions (under surface or adaxial side) are shown in Fig. 3 (P. eous) and Fig 4 (P. ostreatus). They were indistinguishable for the untrained eye. This finding underscores the difficulty of using morphological parameters for separation of species. Thus, needs a molecular approach tn distinouich hetween the twon sneries.

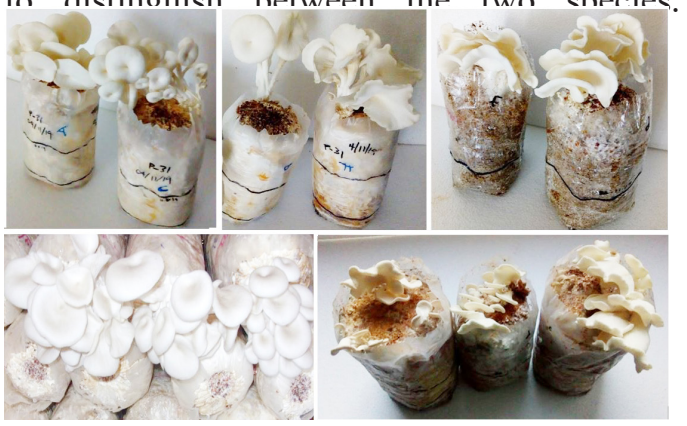

Fig. 1: Emergence and appearance of Pleurotus eous P-31 fruiting bodies in the cropping house (Mg. x0.05).

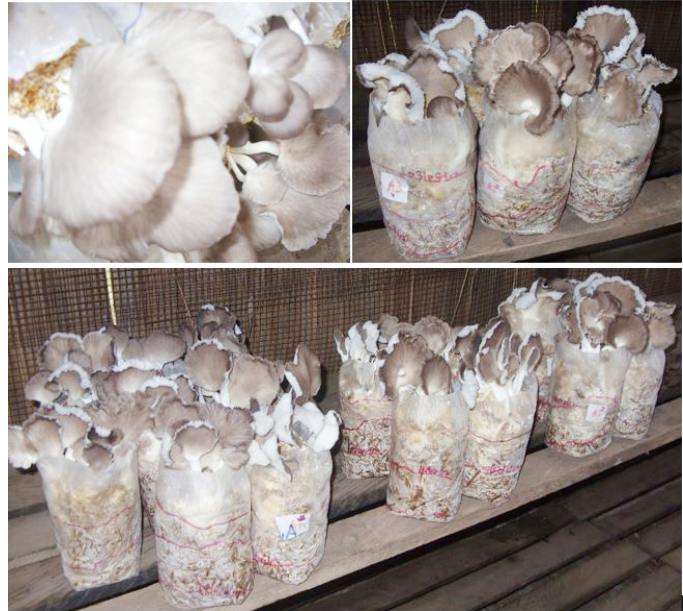

Fig. 2: Emergence and appearance of Pleurotus ostreatus EM-1 fruiting bodies in the cropping house (Mg. x0.05).

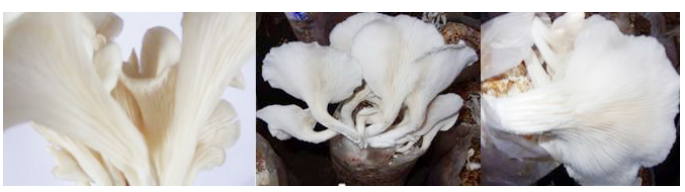

Fig. 3: Gills of P. eous P-31 (Mg. x1/2).

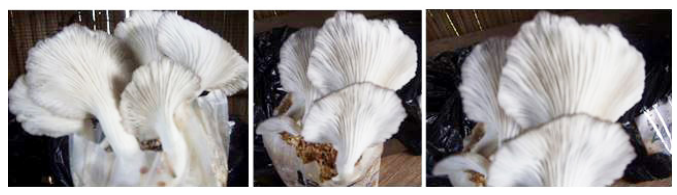

Fig. 4: Gills regions of P. ostreatus EM-1 (Mg. x1/2).

On the other hand, the culture of $P$. eous on agar plate PDA was clearly whitish and cottony in contrast with buff grey ochre for $P$. ostreatus (Plate 5). The other distinguishing features was 
the slow growing $P$. ostreatus which could not cover the plate for the same incubation period of 7 days at $28-30^{\circ} \mathrm{C}$. Clearly this could only offer partial clues to distinguish between the two species.

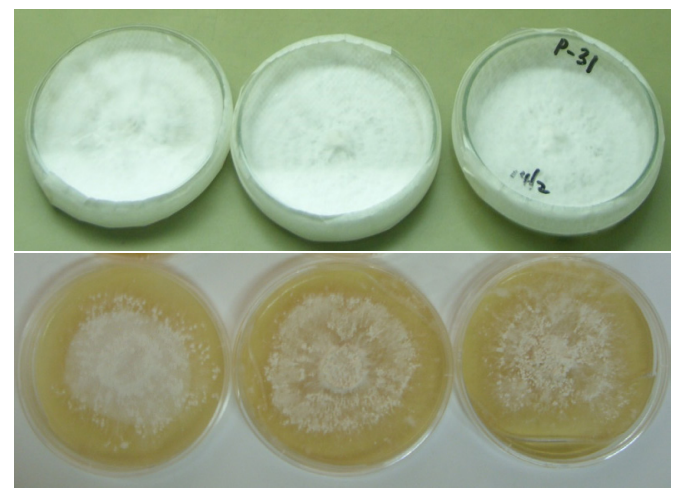

Fig. 5: Vegetative radial growth of Pleurotus species used in the investigation on Potato Dextrose Agar Top: Pleurotus eous P-31; Bottom: P. ostreatus EM-1 (Mg. $\mathrm{x} 1 / 2)$.

PCR performed with ITS I and ITS 4 primers to amplify their ITS region of specimens grown in different substrates showed that the two Pleurotus species could not be separated as they both produced a characteristic band size of $650 \mathrm{bp}$ (Fig. 6) when run with ITS I and ITS 4 primer pairs along Kapa Universal DNA ladder M. Therefore, Hha I, Hinf I and RSa I restrictive enzymes were unable to distinguish between the two mushroom species. Restrictive digestive patterns generated by four restrictive enzymes Hha I, Hinf I, RSa I and Hae III showed that only one restrictive enzyme Hae III was the most effective in segregating $P$. eous P-31 and P. ostreatus EM-1 (Fig. 7).

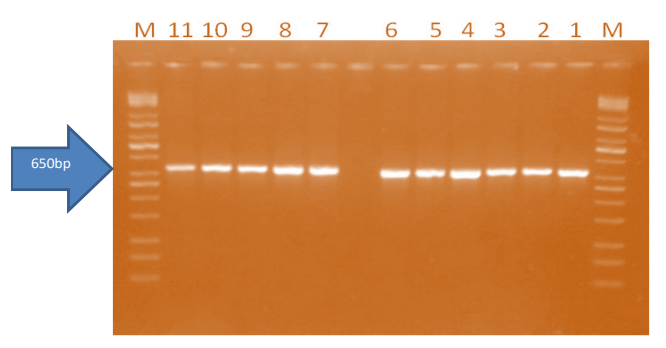

Fig. 6: Gel profile showing ITS 1 and ITS 4 amplification of Mushroom isolates (1 - 11) run alongside Kapa universal DNA ladder (M) i.e., left; Strain EM-1 and right; Strain P-31 respectively.

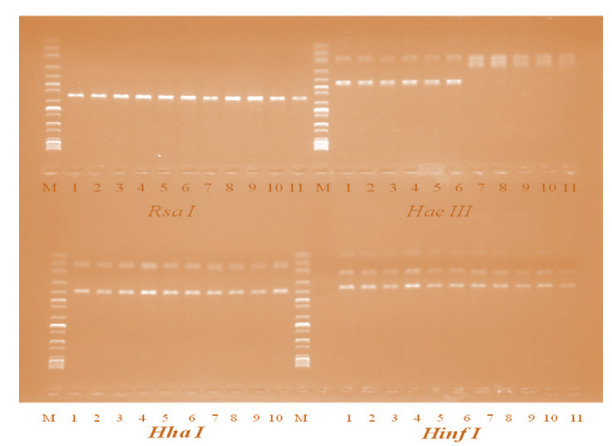

Fig. 7: Gel profile showing restriction patterns generated by four restriction enzymes; Hha I (C), Hinf I (D), Rsa I (A) and Hae III (B) on the samples.

It can be concluded that the two Pleurotus species are different genetically presumably leading the varying to physiological capabilities of bioconversion of same substrate as observed in previous studies by (Wiafe-Kwagyan, 2014; Wiafe-Kwagyan et al., 2016). 


\section{Conclusion}

This is the first record of separation of Ghanaian Pleurotus species on molecular basis. It was clear from a previous preliminary study (Wiafe-Kwagyan, 2014; Wiafe-Kwagyan et al., 2016) that two distinct species of Pleurotus (P. eous and P. ostreatus) on the market used in these investigations on varying substrates have differential bioconversion abilities. Itremains to show, using DNA gene mapping, dendrograms and enzyme production/induction why $P$. eous was a superior utilizer of substrate to produce nutrients from lignocellulose rice waste.

\section{References}

AtikPo, M, Onokpise, O., AbAZinge, M., Louime, C., Dzomeku, M., Boateng, L. \& Awumbilla, B. (2008) Sustainable mushroom production in Africa: A case study in Ghana. African Journal of Biotechnology 7 (3), 249 - 253. Available online at http://www.academicjournals. org/AJB ISSN 1684-5315

Bhatti, M. I., Jiskani, M. M., Wagan, K. H., PaTHAN, M. A. \& Magsi, M. R. (2007) Growth, development, and yield Of Oyster mushroom, Pleurotus ostreatus (Jacq. Ex. Fr.) Kummer as affected by different spawn rates. Pakistan Journal of Botany 39 (7), 2685 - 2692.

Bresinsky, A., Fischer, M., Meixner, B. \& PauLus, W. (1987) Speciation in Pleurotus, Mycologia 79 (2), 234 - 245. DOI: $10.1080 / 00275514.1987 .12025703$

Chang, S. T. \& Miles, P. G. (2004) Mushrooms: Cultivation, nutritional value, medicinal effect and environmental impact. ( $2^{\text {nd }}$ ed.). CRC Press Boca Raton. pp 451

Daba, A. S, Kabeil, S. S, Botros, W. A \& El-SaAdani, M. A (2008) Production ofmushroom (Pleurotus ostreatus) in Egypt as source of nutritional and Medicinal food. World journal of Agricultural Research. 4, 630 - 634.

Hung, P. V. \& NHI, N. N. Y. (2012) Nutritional composition and antioxidant capacity of several edible mushrooms grown in the Southern Vietnam. International Food Research Journal 19 (2), 611 - 615.

IRAÇABAL, B., ZERVAKIS, G. \& LABARE' RE, J. (1995) Molecular systematic of the genus Pleurotus: analysis of the restriction polymorphism in ribosomal DNA. Microbiology 141, $1479-1490$.

Jesenak, M., UrbanceK, S., Majtan, J., Banovcin, P. \& Hercogova, J. (2015) $\beta$-Glucan-based cream (containing pleuran isolated from $\mathrm{Pleu}$ rotus ostreatus) in supportive treatment of mild-to-moderate atopic dermatitis. Journal of Dermatological Treatment 10,1-4.

Jongman, M, Khare, K. B. \& Loeto, D. (2018) Oyster mushroom cultivation at different production systems: A Review. European Journal of Pharmaceutical Sciences 5 (5), 72 -79. ISSN 2349-8870

KANG, S. W. (2004) What is oyster mushroom: Mushroom Growers' Handbook. P.56 Edible and Medicinal Mushrooms, Accra, Ghana, March 24-28, Abstract, 68

Khan, A. \& Tania, M. (2012) Nutritional and Medicinal Importance of Pleurotus Mushrooms: A n Overview. Food Reviews International 28, 313 - 329. DOI: 10.1080/87559129.2011.637267

Kim, S. P., Kang, Y. M., Kim, H. J., Nam, S. H. \& Friedman, M. (2011) Composition and Mechanism of Antitumor Effects of Hericium erinaceus Mushroom Extracts in Tumor-Bearing Mice. Journal of Agricultural and Food Chemistry. 59, 9861 -9869. dx.doi. org/10.1021/jf201944n

Kortei, N. K., Odamtten, G. T., Obodai, M. \& WiAfE- KWAGYAN, M. (2016) Nutritional qualities and shelf-life extension of Gamma irradiated dried Pleurotus ostreatus (Jacq. Ex. Fr.) Kummer preserved in two different storage packs. J. Food Sci. Technol. 5 (1), 9 - 16. DOI: $10.13189 /$ fst.2017.050102

Manpreet, K, Giridhar, S. \& Khanna, P. K. (2004) In vitro and in vivo antioxidant potentials of 
Pleurotus florida in experimental animals. Mushroom Resources 13, 21 - 26.

Nasiruddin, M, Sultana, M. S, Ali Haydar, F.m, Bodrul, I. M. \& Ahmed I.(2018) Analysis of nutritional composition and antioxidant activity of oyster mushrooms grown in Bangladesh. International Journal of Food Sciences and Nutrition 3 (6), 223 - 229.

Nayana, J. \& Janardhanan, K. K. (2000) Antioxidant and antitumour activity of Pleurotus florida. Current Science 79, 941 - 943.

Nuhu, A., Ruhul, A., Asaduzzaman, K., Ismot, A., Mija, S., M In, Woong, L. \&Tae S. L. (2008) Nutritional Analysis of Cultivated Mushrooms in Bangladesh - Pleurotus ostreatus, Pleurotus sajor-caju, Pleurotus florida and Calocybe indica. Mycobiology 36 (4), 228 - 232.

Obinna-Echem, P. C. \& Chukunda, F. A. (2018) Nutrient Composition of Mushroom: Pleurotus ostreatus (Jacaum, ex. Fr. Kummer) grown on Different Agricultural Wastes. Agricultural. Food Science 5 (1), 1 - 5.

Obodai, M. (1992) Comparative studies on the utilization of agricultural waste by some mushrooms (Pleurotus and Volvariella species). MPhil. Thesis, Department of Botany, University of Ghana, Legon.

Obodai, M., Owusu, E., Schiwenger, G. O., Asante, I. K. \& Domeku, M. (2014) Phytochemical and mineral analysis of 12 cultivated oyster mushrooms (Pleurotus species). Advances in Life Science and Technology 26, 35 - 42.

Obodai, M. \& Vowoto, K. A. (2002) Performance of different strains of Pleurotus species under Ghanaian conditions. African Journal of Food Science 7 (3), 98 - 100.

OECD (2005) Consensus Document on the Biology of Pleurotus spp. (Oyster Mushroom). Environment Directorate Joint Meeting of the Chemicals Committee and the Working Party on Chemicals, Pesticides and Biotechnology. ENV/JM/MONO (17). Series on Harmonisa- tion of Regulatory Oversight in Biotechnology No. 34.

Osarenkhoe, O. O., Aroye, O. J. \& Akande T.D. (2014) Ethnomycological Conspectus of West African Mushrooms: An Awareness Document. Advances in Microbiology 4, 39-54. http://dx.doi.org/10.4236/aim.2014.41008.

Oyetayo, F. L., Akindahunsi, A. A. \& Oyetayo, V. O. (2007) Chemical profile and amino acids composition of edible mushrooms Pleurotus sajor-caju. Nutrition and Health, 18, 383 - 389.

Patel, Y., Naraian, R. \& Singh, V. K. (2012) Medicinal Properties of Pleurotus Species (Oyster Mushroom): A Review. World Journal of Fungal and Plant Biology 3 (1), 01 - 12, DOI: 10.5829/idosi.wjfpb.2012.3.1.303.

Patil, S. S., Ahmed, S. A., Telang, S. M. \& Baig, M. M. V. (2010) The nutritional value of Pleurotus ostreatus (Jacq.: Fr.) Kumm cultivated on different lignocellulosic agro-wastes. Innovative Romanian Food Biotechnology 7, 66 - 76.

Piska, K., Sulkowska-Ziaja, K., \& MuszyŃSKa, B. (2017) Edible mushroom Pleurotus ostreatus (Oyster mushroom) - its dietary significance and biological activity. ACTA Scientiarum Polonorum Hortorum Cultus 16 (1), 151 - 161.

RANDive, S. D. (2012) Cultivation and study of growth of oyster mushroom on different agricultural waste substrate and its nutrient analysis. Advances in Applied Science Research 3, 1938 - 1949.

Roupas, P., Keogh, J., Noakes, M., Margetts, C. \& TAYlOR, P. (2012) The role of edible mushrooms in health: evaluation of the evidence. Journal of Functional Foods 4, 687 - 709. https://doi.org/10.1016/j.jff.2012.05.003.

Shukla, S. \& A. K. JAItly (2011) Morphological and biochemical characterization of different oyster mushroom (Pleurotus spp.) Journal of Phytology 3, $18-20$. 
Vilgalys, R., Smith, A., Sun, B. \& Miller, O. K. (1993) Intersterility groups in the Pleurotus ostreatus complex from the continental United States and adjacent Canada. Canadian Journal of Botany 71, 113 - 128.

Wiafe-Kwagyan, M. (2014) Comparative bioconversion of rice lignocellulosic waste and its amendments by two oyster mushrooms (Pleurotus species) and the use of the spent mushroom compost as bio-fertilizer for the cultivation of tomato, pepper, and cowpea. $\mathrm{PhD}$. Thesis, Department of Botany, University of Ghana, Legon.

Wiafe-Kwagyan, M., Obodai, M., Odamtten, G. T. \& Kortei, N. K. (2016) The potential use of rice waste lignocellulose and its amendments as substrate for the cultivation of Pleurotus eous Strain P-31in Ghana. International Journal of advances in Pharmacy, Biology and Chemistry 5 (2), 116 - 130.
Wiafe-Kwagyan, M., Odamtten, G. T., Obodai, M. \& Owusu E. (2017) Rice (Oryza sativa) wastes management in Ghana using oyster mushroom. Lambert Academic Publishing (LAP) OmniScriptum Publishing Germany. pp 102. ISBN:978-620-02234-7.

Wong, J. M. W, Kendall, C. W. C, Desouza, R., Emam, A., Marchie, A., Vidgen, E, Holmes, C. \& Jenkins, D. J. A. (2010) The effect on the blood lipid profile of soy foods combined with a prebiotic: a randomized controlled trial. $\mathrm{Me}$ tabolism 59, 1331 - 1340.

Zervakis, G., Sourdis, J. \& Balis, C. (1994) Genetic variability and systematics of eleven Pleurotus species based on isozyme analysis. Mycological Research 98, 329-341.

Received 09 Oct 20; revised 17 Dec 20. 